\title{
Scaling-up PrEP Delivery in Sub-Saharan Africa: What Can We Learn from the Scale-up of ART?
}

\author{
${\text { Gabrielle } \text { O'Malley }^{1} \cdot \text { Gena Barnabee }^{1} \cdot \text { Kenneth Mugwanya }}^{1}$
}

Published online: 22 February 2019

(C) The Author(s) 2019, corrected publication 2019

\begin{abstract}
Purpose of Review Clinical trials have found that PrEP is highly effective in reducing risk of HIV acquisition across types of exposure, gender, PrEP regimens, and dosing schemes. Evidence is urgently needed to inform scale-up of PrEP to meet the ambitious WHO/UNAIDS prevention target of 3,000,000 individuals on PrEP by 2020 .

Recent Findings Successful models of delivering HIV services at scale evolved from years of formal research and programmatic evidence. These efforts produced lessons-learned relevant for scaling-up PrEP delivery, including the importance of streamlining laboratory tests, expanding prescription and management authority, differentiating medication access points, and reducing stigma and barriers of parental consent for PrEP uptake. Further research is especially needed in areas differentiating PrEP from ART delivery, including repeat HIV testing to ensure HIV negative status and defining and measuring prevention-effective adherence. Summary Evidence from 15 years of ART scale-up could immediately inform a public health approach to PrEP delivery.
\end{abstract}

Keywords Pre-exposure prophylaxis (PrEP) · Scaling-up $\cdot$ PrEP implementation · Sub-Saharan Africa $\cdot$ HIV/AIDS $\cdot$ Anagogical reasoning

\section{Introduction}

The scale-up of antiretroviral therapy (ART) over the past 20 years is one of the biggest public health achievements of the century $[1,2]$. Although highly active antiretroviral therapy became widely available in 1996 in high-income countries, access was minimal in sub-Saharan Africa (SSA) where the HIV/AIDS burden was highest [3]. In 2000, approximately $6600 \mathrm{HIV}$-infected individuals were on treatment in SSA as compared to 664,000 in Europe and the Americas [4]. International advocacy efforts for universal ART access gained steady momentum with landmark initiatives such as the World Health Organization (WHO) 3 by 5 initiative, the establishment of the global fund to fight HIV, tuberculosis and malaria, and the President's Emergency Plan for AIDS Relief (PEPFAR). Even amidst these calls to action and significant

This article is part of the Topical Collection on The Science of Prevention

Gabrielle O'Malley

gomalley@uw.edu

1 Department of Global Health, University of Washington, Seattle, WA, USA dedication of funds, reservations persisted about the promotion of ART in Africa, centering around the cost and complexity of treatment, weak African health systems, human resource constraints, and likely poor adherence to treatment $[5,6]$. Partially in response to these concerns, initial global investments in ART delivery were focused on "centers of excellence," mainly in tertiary hospitals located in major cities. While treatment for people living with HIV/ AIDS (PLWHA) in SSA did increase to 2,950,000 by 2008 [7], this figure represented only $44 \%$ of those needing treatment at that time. It became increasingly apparent that additional approaches would be necessary to truly achieve ART access at scale.

In 2010, the UNAIDS Secretariat and the WHO launched "Treatment 2.0," an initiative to simplify and optimize ART delivery based on the previous decade of programmatic and clinical evidence and experience [8]. Since then, global and national scale-up efforts have frequently moved ahead of evidence provided by formal implementation trials $[9,10]$. By 2017 , there were approximately $15,000,000$ people in subSaharan Africa on ART [11], significantly reducing morbidity and mortality due to HIV $[1,12]$. The increase in ART coverage has also contributed to prevention, as individuals with suppressed viral load do not transmit the virus to others [13]. 
However, the percentage of people living with HIV who are virally suppressed is not yet sufficient to achieve epidemic control at the population level, and it will be necessary to intensify other prevention efforts as well [14].

Since 2012, the world has had access to another biobehavioral prevention technology to help achieve epidemic control through the use of tenofovir-based pre-exposure prophylaxis (PrEP) [15-17]. Clinical trials have found that PrEP is highly effective in reducing risk of HIV acquisition across types of exposure, gender, PrEP regimens, and dosing schemes [18], and attention has turned to questions of how to optimize PrEP implementation [19-22]. There are now dozens of implementation research and demonstration projects either planned or underway across SSA and in multiple populations $[19,23]$. The results of these projects will undoubtedly be helpful in moving the implementation field forward; however, many of them are not scheduled to be completed for several years. Meanwhile, in order to reduce new infections by $75 \%$ in 2020 as compared to 2010, UNAIDS has called for a rapid acceleration of PrEP delivery to reach $3,000,000$ people as one of the five pillars of combination prevention [24].

A lack of formal implementation research results need not necessarily stymie the scale-up of PrEP delivery. In fact, the linear approach typically advocated by academics that moves from efficacy to effectiveness under controlled conditions to scaling to population level may not necessarily be ideal $[25 \bullet$, 26]. The characteristics that cause an intervention to be successful in efficacy or effectiveness research studies (e.g., intensive, supplementary staffing, highly standardized, tightly monitored) are fundamentally different from, and often at odds with, programs that succeed in population-based effectiveness settings (e.g., having broad appeal, being adaptable for both participants and intervention agents) [26]. In scalingup PrEP delivery, as in ART delivery, the interconnectedness and dynamic interactions of actors closely resemble the characteristics of complex adaptive systems, wherein as delivery of the intervention progresses, population perceptions of the intervention change (both those receiving and those providing) which further provide different optimal ways of delivering the intervention [25••, 27-29]. In this environment, a "learning by doing" approach enables the context-specific adaptations to emerge [30, 31].

Given the current lack of evidence available for PrEP delivery at scale in SSA, how can we go about "doing" in the most effective way? Literature from psychology, cognitive, political and computer science, law and business explicitly describes the power of analogical reasoning for learning, decision making, and strategy development [32-36]. Though the global health literature is much less explicit in their use, drawing timely and accurate analogies between the scale-up of ART services and current efforts to scale-up PrEP could significantly increase the rate at which the highest priority populations have access to this important HIV prevention method [37]. The purpose of this review article is to summarize "lessons learned" during 15 years of scaling-up ART in SSA and to describe how they may or may not apply to PrEP scale-up. The hope is that such systematic comparisons will lead to fast-tracking safe and effective delivery of PrEP at scale so that its HIV prevention potential is soon realized at the population level. Key lessons from ART scale-up which are immediately applicable to PrEP delivery are discussed below and summarized in Table 1.

\section{Minimize Laboratory Tests}

Clinical trials and demonstration projects proving the efficiency and effectiveness of bio-medical interventions typically include an array of laboratory tests both to monitor patient safety as well as to provide data for research publications. Once the intervention has been proven safe and implementation possible, a more minimalist approach to laboratory monitoring must be considered to ensure scale-up is feasible. In high-income settings, ART patients often receive an array of laboratory tests on a quarterly basis, including viral load, CD4 counts, liver and renal function tests, and whole-blood counts [38]. However, in SSA, it would not have been possible to implement this protocol widely due to weaker laboratory infrastructure and costs. Not wanting limited laboratory infrastructure to unduly restrict access to ART, the WHO significantly simplified its HIV treatment and laboratory monitoring guidelines over the past two decades. In 2002, WHO guidance recommended a broad range of laboratory requirements for ART, prioritized in four categories: absolute minimum, basic recommended, desirable, and optional tests [39]. Subsequent WHO guidance has progressively emphasized a symptomdirected approach to laboratory monitoring of safety and toxicity for most ARV regimens, including for TDF-containing regimes that is part of the current PrEP formulation $[15,40]$. Although empiric evidence on utility and frequency of laboratory monitoring is limited, one randomized trial which compared laboratory and clinical monitoring to clinically driven monitoring in Uganda and Zimbabwe found that ART could be given safely without routine laboratory tests to save more lives in Africa [41].

In thinking about PrEP delivery, policy makers and program implementers should be similarly pragmatic and dramatically simplify laboratory requirements in order to reduce barriers to PrEP uptake. The WHO 2017 guidance suggests a range of laboratory tests every 3-6 months for those on PrEP including for HIV, creatinine clearance, HBV, HCV, STIs, and pregnancy [42]. However, the majority of persons for whom PrEP is most useful are likely to find it challenging to obtain these laboratory tests this frequently in public health facilities and health providers will be less likely to embrace 
Table 1 Key lessons learned from scaling up ART in SSA and potential applications to the scale-up of PrEP

\begin{tabular}{lc}
\hline Lessons learned from ART delivery scale-up & Application to PrEP delivery scale-up \\
\hline $\begin{array}{l}\text { Scaled implementation required streamlining and } \\
\text { minimizing laboratory tests. }\end{array}$ & $\begin{array}{c}\text { Target population for PrEP are young and healthy } \\
\text { with less likelihood of comorbid conditions }\end{array}$ \\
$\begin{array}{l}\text { Symptom-directed approaches to laboratory } \\
\text { than those on ART }\end{array}$ \\
$\begin{array}{cc}\text { monitoring of safety were adopted to reduce } \\
\text { burden and costs to health system and clients. }\end{array}$ & $\begin{array}{c}\text { monitoring will safely reduce barriers and } \\
\text { costs to health system and clients. }\end{array}$
\end{tabular}

Task-shifting from doctors to nurses was proven safe and dramatically increased access to ART.

Differentiated models of ART service delivery (including non-clinic-based services) have been essential to reducing burden on the health system and increasing access to services for those in need.

Overly cautious adherence preparation for individual clients created barriers to uptake and a "Test and Start" approach has been adopted. A range of adherence support strategies have been implemented.
PrEP is much less complicated and better tolerated than ART. Shifting PrEP prescribing authority from NIMART nurses to other health cadres will increase PrEP access.

Differentiated PrEP service delivery models, (including non-clinic-based services) will be even more important to achieve PrEP delivery at scale as most clients will be healthy and not seeking other clinical services.

Minimize emphasis on 'willingness to adhere' as requirements to start and re-start PrEP. Individual and public health concerns for interrupted adherence are importantly different for PrEP compared to ART.

Additional considerations for PrEP

Current safety and HIV epidemiologic data suggest HIV testing may be the only essential component of minimal lab safety package. Studies are needed to evaluate the safety of HIV testing strategies for PrEP users, including moving follow-up HIV testing from clinical settings to home-based HIV self-testing

Nurses working in family planning, maternal child health, anti-natal, and STI clinics are well-placed to provide PrEP alongside other reproductive health services. Models shifting PrEP delivery from nurses to community health workers and pharmacists should be developed, implemented and assessed.

Non-clinic-based service delivery models (e.g. pharmacies, community points, tele-health/-medicine, private sector) used elsewhere should be tried in African settings. The education and social sectors should be engaged in demand and awareness creation, identification of potential users.

PrEP is not intended for lifelong use but rather periods of risk. Viral mutations from interrupted adherence will be very rare. PrEP delivery requires a shift in thinking around 'successful' adherence at the individual and population level compared to adherence in ART delivery. Family planning may offer a more useful frame of reference for thinking about successful PrEP adherence.

Lowered age of consent and explicit policies and Lowered age of consent and explicit policies and guidelines were necessary to reduce barriers for adolescent access to ART. guidelines will be necessary to reduce barriers for adolescent access to PrEP.

Adolescent girls at especially high risk of HIV may also be those for whom parental consent is a significant barrier. Consider explicitly linking lowered age of consent to related services that may be accessed alongside PrEP (e.g., HIV testing, family planning, mental health, ART, post-violence).

Stigma has been a barrier to HIV testing and treatment. Campaigns targeting "high risk populations" may have inadvertently contributed to stigmatizing people living with HIV as well as the sexual behavior through which their HIV was acquired.

The same stigma associated with HIV is also a barrier for PrEP uptake and persistence. Reduce emphasis on 'risk' and 'risky' behaviors in messaging for PrEP.
Shift public health messaging about PrEP from an emphasis on "risky behavior" to sex-positive, empowering language. Invest in strategies to increase community awareness to normalize pill taking for prevention.
PrEP as a feasible HIV prevention intervention if they fear its safe implementation requires frequent laboratory monitoring. TDF-based PrEP is demonstrably very safe, with the most frequently reported side effect being gastro-intestinal symptoms which are normally self-limiting within 1-2 weeks of PrEP initiation [16, 43]. The risk of severe toxicities, including kidney injury and decrease in bone mineral density which were the initial main concern for PrEP, have been shown to be rare and limited both in frequency $(<2 \%)$ and magnitude [44-46]. The specific components of the PrEP minimal safety package may evolve over time with the emergence of new testing technologies and will vary across contexts, depending on such things as cost, infrastructure, and treatment availability. For example, testing for hepatitis $\mathrm{B}$ or $\mathrm{C}$ as a component of routine PrEP delivery seems counterproductive in a setting where no treatment is available, where healthcare providers are overstretched, and health systems severely underresourced. The favorable safety profile for PrEP coupled with the fact that PrEP users are mostly young healthy persons supports a pragmatic and minimalist approach for laboratory testing in PrEP roll-out. For example, the Kenya guidelines for PrEP require HIV testing but are permissive of initiating and 
continuing PrEP without kidney function and hepatitis B testing if laboratory testing is not available [47]. Formal implementation science studies could more formally test the comparative cost effectiveness of various models, including no testing or only annual kidney safety monitoring with targeted testing for those with known risk factors for kidney injury.

Regular HIV testing is an essential component of PrEP delivery necessary to reduce the risk of antiretroviral resistance if HIV infection is present prior to PrEP, in which case PrEP will not be started, or occurs while prescribed PrEP, in which case it will be discontinued. Current guidelines recommend quarterly HIV testing for individuals on PrEP, operationalized mostly with provider-led clinic-based testing. Incorporating novel HIV testing technologies like HIV self-testing could result in greater implementation efficiency (reducing clinic visits and saving staffing and participant costs) in already overburdened health systems while maintaining fidelity of PrEP delivery. Ongoing studies experimenting a hybrid approach with HIV self-testing to replace quarterly clinic-based HIV testing with six-monthly clinic-based and quarterly HIV self-testing (Clinicaltrials.gov: NCT03593629) will help inform the safety and utility of this approach.

\section{Task Shifting}

Early programs of ART delivery in sub-Saharan Africa were physician intensive. Several years into the launch of PEFPAR, it became clear that bringing ART delivery to scale would require changing that model to enable nurses to care for and prescribe ART. Multiple countries started training nurses in nurse initiation and management of ART (NIMART), and by 2010, there was extensive evidence as to the safety, feasibility, and desirability of nurses prescribing ART [48]. Evidence showed no difference in patient outcomes (virologic failure, mortality, toxicity failure) between physician-led and nurse-led initiation of ART and management of HIV care [49] and several studies showed improved patient satisfaction in nonphysician initiated and managed care $[50,51]$. The accumulation of this formal evidence eventually led to official policy changes about who could prescribe ART.

Because PrEP is an antiretroviral medication, many projects in Africa have identified HIV physicians, clinical officers, and NIMART nurses as the ones who should prescribe PrEP and those most likely to become experts in its delivery. Whereas this may be the most efficient use of human resources in some contexts, for example PrEP delivery for sero-discordant couples at ART clinics, too closely linking PrEP with ART prescription and management could discourage non-ART health providers from prescribing and managing PrEP, either formally through regulatory requirements or informally through assumptions that PrEP is as complicated as ART. Unnecessary restriction of PrEP prescription and refill authority will significantly constrain the reach of PrEP delivery and risk further over taxing ART service providers. Since PrEP is generally very well-tolerated and the risk of severe adverse events including kidney impairment are very rare [43, 52], moving quickly to PrEP provision by nonNIMART-trained nurses and other healthcare cadres should be strongly encouraged. Nurses working in family planning, maternal child health, anti-natal, STI, and other clinics where there is routine HIV testing would be very well-placed to implement rapid screening for and initiation and follow-up of PrEP clients [53]. Implementation research should focus on how best to motivate and engage healthcare workers to consider integration of PrEP provision into sexual and reproductive health and other health services. Pharmacists and community health workers working in community settings may better meet the needs of populations historically less likely to seek services at a health facility (see section below on differentiated service delivery for further discussion). Policy makers concerned with non-clinical specialists routinely providing refills and ongoing support for individuals wanting to take PrEP can look to the evidence from ART scale-up that demonstrates non-specialist medication delivery can be both safe and effective and rapidly move forward non-clinic-based approaches of PrEP delivery. Once implemented, programmatic data from these various approaches produced in different contexts as well as more intensively collected implementation research data can inform ongoing program refinement.

\section{Differentiated Models of Service Delivery}

Public ART services in SSA were initially concentrated in clinics in major hospitals, which were very quickly inundated with patients. It soon became apparent that overly crowded ART clinics, as well as long distances between client homes and these centralized ART delivery points, threatened access to and retention in HIV care and treatment. In response, a range of service delivery models differentiated by the service frequency, location, intensity, provider, or some combination of these [54] have been implemented to decongest health facilities, bring ART closer to where clients work and live, and reduce the time burden and transaction costs of clients needing HIV treatment. Models have been tailored to respond to differences in clinical characteristics of clients (stable, unstable, comorbidities), sub-population (men, women, children, key populations), and context (urban, rural, stability, epidemic type) $\left[55^{\circ}\right]$. 
Innovations in ART differentiated service delivery have included (1) facility-based individual models, for example, where ART refill visits have been separated from clinical consultations so as to "fast-track" ART refills [56] and with appointment spacing extended from 3 to 6 months [57, 58]; (2) models where ART refills and some clinical consultations are provided to individuals outside of healthcare facilities, for example using drug distribution (CDDP) systems in Uganda $[59,60]$ or home delivery [61]; (3) group models where clients receive their ART refills in a group managed by a lay healthcare staff member, such as in adherence clubs in South Africa [62] and Kenya [63]; and (4) client-managed group models, where clients receive their ART refills in a group but this group is managed and run by clients themselves [56, 64]. Overall, the results of these efforts have shown improved rates of ART coverage and patient satisfaction $[65,66]$ and decreases in loss to follow to follow-up and mortality $[67,68]$.

The need for differentiated service delivery will be crucial for PrEP scale-up as well. Individuals who are not feeling sick and have no HIV diagnosis may be even less inclined than those living with HIV to wait in long health lines and travel to special health facilities. Some of the populations most at risk for HIV (e.g., MSM, CSW, and AGYW) may be especially disinclined to access prevention services at health facilities [19]. Implementers should consider how to modify and scale PrEP service delivery models centered on these and other unique needs of PrEP clients. Recent innovations from outside SSA provide promising models for scale including PrEP in community pharmacy settings [69] and tele-medicine-assisted models in both the public and private health sectors [70]. Early learning from these models suggests PrEP service delivery outside of clinical settings as well as outside the public health sector is feasible and acceptable. Implementation approaches should further consider intersectoral engagement in PrEP service delivery and the potential contribution of education, social, and other sectors in generating demand and awareness, identifying potential users, and as possible delivery points for PrEP provision and follow-up services.

A challenge for non-facility-based PrEP delivery not shared by ART services is the need for repeat HIV testing to confirm ongoing HIV-negative status and hence eligibility for PrEP continuation. As discussed above, further implementation research is needed on improving correct HIV diagnosis at point of service locations with testing algorithms that can be performed rapidly and effectively without expensive equipment or specialized laboratory technicians [71]. HIV self-tests have significant potential in this regard, although current challenges exist with high self-test kit costs and reliability of results due to user performance errors [72]. Increasing the reliability, adoption, and adaptation of HIV-self testing will be key to ensuring feasibility of decentralized and communitybased PrEP services.

\section{Adherence Readiness Concerns and Scaled Uptake}

Adherence is key for the effectiveness of both ART and PrEP. Since the start of ART scale-up in SSA, adherence has justifiably been a central concern as sub-optimal adherence can lead to development of drug-resistant mutations both at the individual and population level [73]. Concerns about individuals being able to take their medication regularly underlay the cautious approach to ART initiation in the early years of scale-up, wherein attending several adherence counseling sessions to demonstrate readiness and commitment to take treatment regularly and correctly was required before ART medication could be prescribed [74, 75]. However, substantial attrition between testing and treatment occurred under this model. In a systematic review of retention outcomes in HIV care between testing and treatment in SSA, Rosen et al. [76] estimated that less than one-third of patients testing positive for HIV but not eligible for ART when diagnosed were retained in preART care continuously, including those patients who did not return for their initial CD4 count results and those in the preparatory phases of ART initiation. After a decade of scale-up, the perceived benefit of ensuring adherence readiness through multiple counseling sessions was outweighed by concerns of lost opportunity to link HIV+ individuals to care with more immediate start of ART; the WHO recommended a "Test and Start" approach, wherein individuals diagnosed with HIV are started on ART immediately [15]. The lesson we can draw from this for PrEP uptake and continuation is to make it as easy as possible for those who request PrEP to get it. Delaying or refusing PrEP due to concerns about willingness to adhere is likely to have a deterrent effect on individuals seeking prevention medication.

In clinical trials and demonstration projects to date, monitoring PrEP adherence has been essential to determining whether it was truly effective. However, transitioning from research to implementation at scale necessitates thinking about PrEP adherence differently. Although a range of ART adherence interventions (e.g., SMS, adherence clubs, economic incentives, and intensified counseling approaches) [77] may be applicable to supporting PrEP clients, PrEP adherence requirements and concerns are fundamentally different from those of ART along several key dimensions. These differences need to be carefully considered as countries calibrate their level of investment in adherence strategies for routine PrEP delivery. First, the public health risk of individual nonadherence is much less for PrEP than for ART. Sub-optimal adherence to PrEP may result in an individual acquiring HIV but evidence suggests instances of viral mutation will be rare [78-81]. Second, unlike ART, PrEP is not intended for lifelong use, but only for seasons of potential HIV exposure. "Prevention-effective PrEP adherence" requires the use of PrEP only during periods of risk exposure and when 
alternative prevention tools, such as condoms or the use of ART to achieve viral suppression by a known HIV-infected partner, are not used [82]. As such, discontinuation of PrEP has different implications for definitions of program success than does the discontinuation of ART. In thinking about what programmatic outcomes constitute successful adherence to PrEP in routine settings, family planning may offer a useful frame of reference. Just as family planning programs have prevented many unplanned pregnancies despite imperfect risk assessment and use of contraception, more HIV will be prevented with PrEP than without it [82]. Further policy discussions, implementation research, and modeling are necessary to generate consensus on acceptable PrEP adherence at the population level.

\section{Parental Consent and PrEP Access for Adolescents}

During the scale-up of ART, requiring parental consent for an HIV test was recognized as a barrier for adolescents who wanted to avoid telling parents about their sexual activity [83-85]. In response, many African countries formally lowered the age of consent for HIV testing from aged 18 to as low as 12 years [85]. However, only one country (Madagascar) also explicitly allows ART treatment without parental consent [84]. Resolving issues surrounding parental consent both for HIV testing and PrEP medication will be equally important for scaling PrEP delivery to this demographic, especially as adolescent girls in SSA are a particularly vulnerable age group for HIV acquisition [20]. Evidence from ART scale-up suggests that where age of consent guidance is limited or vague or policies not well understood, health providers are frequently reluctant to provide services or impose age restrictions based on their own values and judgments [86, 87]. Studies on the provision of HIV counseling, testing, and treatment $[84,85,87]$ as well as of family planning services $[88,89]$ suggest that clear and congruent laws, policies, and guidelines permitting independent consent to both HIV testing and medication will be important to ensure PrEP access and prevention impact across this population. Countries might consider explicitly linking lowered age of consent to related services that may be accessed alongside PrEP (e.g., HIV testing, family planning, mental health, ART, post-violence).

\section{Reduce Stigma and Normalize Use}

From its early days, HIV has been stigmatized as a disease acquired through undesirable (multiple sexual partners) or illegal sexual behavior (as in the case of commercial sex workers and MSM). Targeting high-risk categories in public campaigns can unintentionally fuel stigma and discourage individuals from testing for HIV, because they do not identify as or want to be associated with one of these groups [37, 90]. Stigma associated with HIV has also impacted the way HCW interact with the population, further reducing incentives for individuals to be tested for HIV and for those living with HIV to seek care and treatment [91]. Over the course of the response to the HIV epidemic, HIV testing has become increasingly routinized [92], and there is some evidence that societal and self-stigma has decreased as ART coverage has increased [93], although the evidence is mixed [94].

Likewise, strategies to encourage PrEP adoption and adherence must proactively consider the role of stigma in uptake and delivery. In several contexts, PrEP stigma has been identified as the most significant community level barrier to PrEP uptake and adherence [95-97]. PrEP programs, policy and research, must be careful not to reinforce or amplify this stigma [98•]. Currently, most PrEP messaging is for individuals at "very high risk." The extent to which PrEP users come to be perceived by the community (including health care workers) as "high risk" or "promiscuous" could greatly undermine PrEP uptake [19, 20]. Evidence suggests that societal stigma associated with PrEP will influence individuals to underestimate their risk for HIV (and hence eligibility for PrEP) as they seek to reduce their association with these stigmatized groups [37]. Changing PrEP messaging to make it more engaging, sex positive, and intimacy focused will greatly increase the likelihood that PrEP uptake will be achieved at the scale necessary for population level prevention impact [20, 99]. Changing PrEP messaging to focus on those wanting to take responsibility for their sexual health and to reduce concerns around HIV infection constructs PrEP as a socially desirable behavior and may even promote condom use by promoting what has been termed a "preventionist identity" [98].

\section{Conclusion}

With broad dissemination and uptake, PrEP has significant potential to reduce population level HIV incidence. Just as PrEP can only prevent HIV at the individual level if taken effectively, PrEP can only significantly impact epidemic control if it is scaled rapidly and effectively to reach populations experiencing high levels of HIV incidence. Results of ongoing and future implementation research will be instrumental in finetuning PrEP delivery to maximize benefit while minimizing costs. Meanwhile, rapid introduction and scaling of PrEP programs to meet global targets can be facilitated by borrowing evidence from the scale-up of ART and using programmatic data to rapidly assess effectiveness in real time and modify delivery models in different contexts. Experience with ART service delivery suggests that scaling will require both simplifying and diversifying approaches so that PrEP delivery is feasible for health systems and accessible to the various 
populations for whom PrEP is the best prevention tool. As countries with high HIV prevalence make progress in implementing a public health approach to PrEP, the context of PrEP delivery will evolve. Developing streamlined data collection systems will be essential to capture the dynamic interaction between context and delivery and to ensure ongoing "learning by doing" occurs.

\section{Compliance with Ethical Standards}

Conflict of Interest The authors declare that they have no conflicts of interest.

Human and Animal Rights and Informed Consent This article does not contain any studies with human or animal subjects performed by any of the authors.

Open Access This article is distributed under the terms of the Creative Commons Attribution 4.0 International License (http:// creativecommons.org/licenses/by/4.0/), which permits use, duplication, adaptation, distribution and reproduction in any medium or format, as long as you give appropriate credit to the original author(s) and the source, provide a link to the Creative Commons license and indicate if changes were made.

Publisher's Note Springer Nature remains neutral with regard to jurisdictional claims in published maps and institutional affiliations.

\section{References}

Papers of particular interest, published recently, have been highlighted as:

- Of importance

•- Of major importance

1. Fauci AS, Eisinger RW. PEPFAR - 15 Years and Counting the Lives Saved. N Engl J Med. 2018;378(4):314-6. https://doi.org/10. 1056/NEJMp1714773.

2. Bendavid E. Past and Future Performance: PEPFAR in the Landscape of Foreign Aid for Health. Current HIV/AIDS reports. 2016;13(5):256-62. https://doi.org/10.1007/s11904-016-0326-8.

3. Weller I. Delivery of Antiretroviral Therapy in Sub-Saharan Africa. Clin Infect Dis. 2006, 43(6):777-8. https://doi.org/10.1086/ 507113.

4. Baggaley R, Hensen B, Ajose O, Grabbe KL, Wong VJ, Schilsky A, et al. From caution to urgency: the evolution of HIV testing and counselling in Africa. Bull World Health Organ. 2012;90(9):6528b. https://doi.org/10.2471/blt.11.100818.

5. McCoy D, Chopra M, Loewenson R, Aitken J-M, Ngulube T, Muula A, et al. Expanding Access to Antiretroviral Therapy in Sub-Saharan Africa: Avoiding the Pitfalls and Dangers, Capitalizing on the Opportunities. Am J Public Health. 2005;95(1):18-22. https://doi.org/10.2105/AJPH.2004.040121.

6. Creese A, Floyd K, Alban A, Guinness L. Cost-effectiveness of HIV/AIDS interventions in Africa: a systematic review of the evidence. Lancet. 2002;359(9318):1635-42. https://doi.org/10.1016/ S0140-6736(02)08595-1.
7. UNAIDS. Towards Universal Acess: Scaling up Priority HIV/ AIDS Interventions in the Health Sector. UNAIDS. 2009. http:// data.unaids.org/pub/report/2009/20090930_tuapr_2009_en.pdf. Accessed 5 June 2018.

8. The treatment 2.0 framework for action: catalysing the next phase of treatment, care and support. 2011. http://apps.who.int/iris/ bitstream/handle/10665/44640/9789241501934_eng.pdf; jsessionid=A3D92348E6F0A91B9FD63D78778 BB050? sequence $=1$. Accessed May 202018.

9. Ford N, Calmy A, Mills EJ. The first decade of antiretroviral therapy in Africa. Glob Health. 2011;7(1):33. https://doi.org/10.1186/ 1744-8603-7-33.

10. Harries AD, Ford N, Jahn A, Schouten EJ, Libamba E, Chimbwandira F, et al. Act local, think global: how the Malawi experience of scaling up antiretroviral treatment has informed global policy. BMC Public Health. 2016;16(1):938. https://doi.org/10. 1186/s12889-016-3620-x.

11. UNAIDS. AIDSinfo. http://aidsinfo.unaids.org/?did= $5757 \mathrm{e} 25 \mathrm{~b} 2 \mathrm{~d} 8 \mathrm{e} 328007747 \mathrm{ce} 1 \& \mathrm{r}=$ world-continents \& $\mathrm{t}=\mathrm{null} \& \mathrm{tb}=$ $\mathrm{d} \& \mathrm{bt}=\mathrm{drli} \& \mathrm{ts}=\& \mathrm{tr}=\mathrm{w}$ orld $-\mathrm{continents} \& \mathrm{aid}=$ 5 ae0712562abc329969a8de0\&sav=Population:\%20A11\% 20ages\&tl=1

12. Bendavid E, Bhattacharya J. PEPFAR in Africa: An Evaluation of Outcomes. Ann Intern Med. 2009;150(10):688-95 http://annals. org/aim/fullarticle/744499/president-s-emergency-plan-aids-reliefafrica-evaluation-outcomes.

13. Eyawo O, de Walque D, Ford N, Gakii G, Lester RT, Mills EJ. HIV status in discordant couples in sub-Saharan Africa: a systematic review and meta-analysis. Lancet Infect Dis. 2010;10(11):770-7. https://doi.org/10.1016/s1473-3099(10)70189-4.

14. UNAIDS. 90-90-90 an Ambitious Treatment Target to Help End the AIDS Epidemic. Geneva2014 October. Report No.: JC2684.

15. World Health Organization. Guideline on when to start antiretroviral therapy and on pre-exposure prophylaxis for HIV. WHO, Geneva. 2015. http://apps.who.int/iris/bitstream/10665/186275/1/ 9789241509565_eng.pdf. Accessed December 302017.

16. Grant RM, Lama JR, Anderson PL, McMahan V, Liu AY, Vargas L, et al. Preexposure chemoprophylaxis for HIV prevention in men who have sex with men. N Engl J Med. 2010;363(27):2587-99. https://doi.org/10.1056/NEJMoa1011205.

17. Baeten JM, Donnell D, Ndase P, Mugo NR, Campbell JD, Wangisi $\mathrm{J}$, et al. Antiretroviral prophylaxis for HIV prevention in heterosexual men and women. N Engl J Med. 2012;367(5):399-410. https:// doi.org/10.1056/NEJMoa1108524.

18. Fonner VA, Dalglish SL, Kennedy CE, Baggaley R, O'Reilly KR, Koechlin FM, et al. Effectiveness and safety of oral HIV preexposure prophylaxis for all populations. AIDS. 2016;30(12): 1973-83. https://doi.org/10.1097/qad.0000000000001145.

19. Cowan FM, Delany-Moretlwe S, Sanders EJ, Mugo NR, Guedou FA, Alary M, et al. PrEP implementation research in Africa: what is new? J Int AIDS Soc. 2016;19(7(Suppl 6)):21101. https://doi.org/ 10.7448/ias.19.7.21101.

20. Celum CL D-DM, McConnell M, , van Rooyen H, Bekker LG, Kurth A, Bukusi E, Desmond C, Morton J, Baeten JM. Rethinking HIV prevention to prepare for oral PrEP implementation for young African women. Journal of the International AIDS Society 2015:18(4Suppl3):20227. Doi: doi:https://doi.org/10.7448/ IAS.18.4.20227.

21. Baeten JM. Amplifying the Population Health Benefits of PrEP for HIV Prevention. J Infect Dis. 2018;217(10):1509-11. https://doi. org/10.1093/infdis/jiy045.

22. Marcus JL, Volk JE, Pinder J, Liu AY, Bacon O, Hare CB, et al. Successful Implementation of HIV Preexposure Prophylaxis: Lessons Learned From Three Clinical Settings. Current HIV/ AIDS reports. 2016;13(2):116-24. https://doi.org/10.1007/s11904016-0308-x. 
23. Ongoing and Planned PrEP Demonstration and Implementation Studies. In: Fact Sheet. AVAC. 2017. https://www.avac.org/ resource/ongoing-and-planned-prep-demonstration-andimplementation-studies. Accessed 23 June 2018.

24. Selke HM, Kimaiyo S, Sidle JE, Vedanthan R, Tierney WM, Shen $\mathrm{C}$, et al. Task-shifting of antiretroviral delivery from health care workers to persons living with HIV/AIDS: clinical outcomes of a community-based program in Kenya. J Acquir Immune Defic Syndr. 2010;55(4):483-90. https://doi.org/10.1097/QAI. 0b013e3181eb5edb.

25.• Chambers DA, Norton WE. The Adaptome: Advancing the Science of Intervention Adaptation. Am J Prev Med. 2016;51(4 Suppl 2): S124-31. https://doi.org/10.1016/j.amepre.2016.05.011 This article provides a thorough discussion of the limitations of the linear pathway from efficacy trials to scaled implementation in diverse settings. It compellingly describes the dynamic role of adaptation and practice-based evidence in increasing the effectiveness of evidenced based intervention as they move to delivery settings.

26. Glasgow RE, Lichtenstein E, Marcus AC. Why don't we see more translation of health promotion research to practice? Rethinking the efficacy-to-effectiveness transition. Am J Public Health. 2003;93(8):1261-7.

27. Paina L, Peters DH. Understanding pathways for scaling up health services through the lens of complex adaptive systems. Health Policy Plan. 2012;27(5):365-73. https://doi.org/10.1093/heapol/ czr054.

28. Castro FG, Barrera M Jr, Martinez CR Jr. The cultural adaptation of prevention interventions: resolving tensions between fidelity and fit. Prev Sci. 2004;5(1):41-5.

29. Brainard J, Hunter PR. Do complexity-informed health interventions work? A scoping review. Implement Sci. 2016;11(1):127. https://doi.org/10.1186/s13012-016-0492-5.

30. Katzenstein D, Koulla-Shiro S, Laga M, Moatti JP. Learning and doing: operational research and access to HIV treatment in Africa. Aids. 2010;24(Suppl 1):S1-4. https://doi.org/10.1097/01.aids. 0000366077.37827.0a.

31. Ilott I, Gerrish K, Pownall S, Eltringham S, Booth A. Exploring scale-up, spread, and sustainability: an instrumental case study tracing an innovation to enhance dysphagia care. Implement Sci. 2013;8:128. https://doi.org/10.1186/1748-5908-8-128.

32. Gavetti G, Rivkin J. How Strategists Really Think: Tapping the Power of Analogy. Harvard Business Review 2005:April. https:// hbr.org/2005/04/how-strategists-really-think-tapping-the-powerof-analogy.

33. Leuzzi F, Ferilli S. A multi-strategy approach to structural analogy making. J Intell Inf Syst. 2018;50(1). https://doi.org/10.1007/ s10844-017-0447-6.

34. Schauer F, Spellman B. Analogy, Expertise, and Experience. The University of Chicago Law Review 2017:84(1).

35. Gentner D, Brem S, Ferguson RW, Markman AB, Levidow BB, Wolff P, et al. Analogical Reasoning and Conceptual Change : A Case Study of Johannes Kepler. J Learn Sci. 1997;g(1):3-40. https://doi.org/10.1207/s15327809j1s0601_2.

36. Hoyos C, Gentner D. Generating explanations via analogical comparison. Psychon Bull Rev. 2017;24(5):1364-74. https://doi.org/10. 3758/s13423-017-1289-5.

37. Golub SA, Operario D, Gorbach PM. Pre-exposure prophylaxis state of the science: empirical analogies for research and implementation. Current HIV/AIDS reports. 2010;7(4):201-9. https://doi. org/10.1007/s11904-010-0057-1.

38. Asboe D, Aitken C, Boffito M, Booth C, Cane P, Fakoya A, et al. British HIV Association guidelines for the routine investigation and monitoring of adult HIV-1-infected individuals 2011. HIV Med. 2012;13(1):1-44. https://doi.org/10.1111/j.1468-1293.2011.00971. $\mathrm{x}$.
39. World Health Organization. Scaling up antiretroviral therapy in resource-limited settings : guidelines for a public health approach. 2003. http://www.who.int/hiv/pub/prev_care/ScalingUp_E.pdf. Accessed 5 June 2018.

40. World Health Organization. Consolidated Guidelines on the Use of Antiretroviral Drugs for Treating and Preventing HIV Infection: Recommendations for a Public Health Approach. Geneva. 2016. http://apps.who.int/iris/bitstream/handle/10665/208825/ 9789241549684 e n g.pd f; s e s s i on id= E12EB5C4DF198A9389F34DBAE12676E3? sequence $=1$. Accessed 13 June 2018.

41. Team DT, Mugyenyi P, Walker AS, Hakim J, Munderi P, Gibb DM, et al. Routine versus clinically driven laboratory monitoring of HIV antiretroviral therapy in Africa (DART): a randomised noninferiority trial. Lancet. 2010;375(9709):123-31. https://doi.org/ 10.1016/S0140-6736(09)62067-5.

42. Fox K, Ferguson J, Ajose W, Singh J, Marum E, Baggaley R. Adolescent consent to testing: a review of current policies and issues in sub-Saharan Africa. HIV and Adolescents: Guidance for HIV Testing and Counselling and Care for Adolescents Living with HIV: Recommendations for a Public Health Approach and Considerations for Policy-Makers and Managers. Geneva: World Health Organization; 2013.

43. Mugwanya KK, John-Stewart G, Baeten J. Safety of oral tenofovir disoproxil fumarate-based HIV pre-exposure prophylaxis use in lactating HIV-uninfected women. Expert Opin Drug Saf. 2017;16(7):867-71. https://doi.org/10.1080/14740338.2017. 1338271.

44. Mugwanya KK, Wyatt C, Celum C, Donnell D, Mugo NR, Tappero $\mathrm{J}$, et al. Changes in glomerular kidney function among HIV-1uninfected men and women receiving emtricitabine-tenofovir disoproxil fumarate preexposure prophylaxis: a randomized clinical trial. JAMA Intern Med. 2015;175(2):246-54. https://doi.org/10. 1001/jamainternmed.2014.6786.

45. Mugwanya KK, Wyatt C, Celum C, Donnell D, Kiarie J, Ronald A, et al. Reversibility of Glomerular Renal Function Decline in HIVUninfected Men and Women Discontinuing EmtricitabineTenofovir Disoproxil Fumarate Pre-Exposure Prophylaxis. J Acquir Immune Defic Syndr. 2016;71(4):374-80. https://doi.org/ 10.1097/qai.0000000000000868.

46. Mulligan K, Glidden DV, Anderson PL, Liu A, McMahan V, Gonzales P, et al. Effects of Emtricitabine/Tenofovir on Bone Mineral Density in HIV-Negative Persons in a Randomized, Double-Blind, Placebo-Controlled Trial. Clin Infect Dis. 2015;61(4):572-80. https://doi.org/10.1093/cid/civ324.

47. http://emtct-iatt.org/wp-content/uploads/2016/09/Guidelines-onUse-of-Antiretroviral-Drugs-for-Treating-and-Preventing-HI.... pdf. Guidelines on the use of antiretroviral drugs for treating and preventing HIV infection in Kenya.

48. Callaghan M, Ford N, Schneider H. A systematic review of taskshifting for HIV treatment and care in Africa. Hum Resour Health. 2010;8:8. https://doi.org/10.1186/1478-4491-8-8.

49. Sanne I, Orrell C, Fox MP, Conradie F, Ive P, Zeinecker J, et al. Nurse versus doctor management of HIV-infected patients receiving antiretroviral therapy (CIPRA-SA): a randomised noninferiority trial. Lancet. 2010;376(9734):33-40. https://doi.org/10. 1016/s0140-6736(10)60894-x.

50. Asfaw E, Dominis S, Palen JG, Wong W, Bekele A, Kebede A, et al. Patient satisfaction with task shifting of antiretroviral services in Ethiopia: implications for universal health coverage. Health Policy Plan. 2014;29(Suppl 2):ii50-8. https://doi.org/10.1093/ heapol/czu072.

51. Suzan-Monti M, Blanche J, Boyer S, Kouanfack C, Delaporte E, Bonono RC, et al. Benefits of task-shifting HIV care to nurses in terms of health-related quality of life in patients initiating antiretroviral therapy in rural district hospitals in Cameroon [Stratall Agence 
Nationale de Recherche sur le SIDA (ANRS) 12110/Ensemble pour une Solidarite Therapeutique Hospitaliere en Reseau (ESTHER) substudy]. HIV Med. 2015;16(5):307-18. https://doi.org/10.1111/ hiv. 12213 .

52. Mugwanya KK, Baeten JM. Safety of oral tenofovir disoproxil fumarate-based pre-exposure prophylaxis for HIV prevention. Expert Opin Drug Saf. 2016;15(2):265-73. https://doi.org/10. $1517 / 14740338.2016 .1128412$

53. Heffron R, Pintye J, Matthews LT, Weber S, Mugo N. PrEP as periconception HIV prevention for women and men. Current HIV/ AIDS reports. 2016;13(3):131-9. https://doi.org/10.1007/s11904016-0312-1.

54. Duncombe C, Rosenblum S, Hellmann N, Holmes C, Wilkinson L, Biot M, et al. Reframing HIV care: putting people at the centre of antiretroviral delivery. Tropical Med Int Health. 2015;20(4):430 47. https://doi.org/10.1111/tmi.12460.

55. Grimsrud A, Bygrave H, Doherty M, Ehrenkranz P, Ellman T, Ferris R, et al. Reimagining HIV service delivery: the role of differentiated care from prevention to suppression. J Int AIDS Soc. 2016;19(1):21484. https://doi.org/10.7448/IAS.19.1.21484 This article summarizes evidence for differentiated models of ART service delivery and how this will be crucial for achieving epidemic control. Evidence of what is needed to scale is applicable to PrEP, which is a much safer regimen than ART.

56. Médecins Sans Frontières. Reaching closer to home: Progress implementing community-based and other adherence strategies supporting people on HIV treatment, 2013. https://www.msf.org/ sites/msf.org/files/reaching closer to home.pdf.

57. Prust ML, Banda CK, Nyirenda R, Chimbwandira F, Kalua T, Jahn A, et al. Multi-month prescriptions, fast-track refills, and community ART groups: results from a process evaluation in Malawi on using differentiated models of care to achieve national HIV treatment goals. J Int AIDS Soc. 2017;20(Suppl 4):21650. https://doi. org/10.7448/IAS.20.5.21650.

58. Mody A, Roy M, Sikombe K, Savory T, Holmes C, Bolton-Moore C, et al. Improved Retention With 6-Month Clinic Return Intervals for Stable Human Immunodeficiency Virus-Infected Patients in Zambia. Clin Infect Dis. 2018;66(2):237-43. https://doi.org/10. 1093/cid/cix756.

59. Mbonye M, Seeley J, Ssembajja F, Birungi J, Jaffar S. Adherence to antiretroviral therapy in Jinja, Uganda: a six-year follow-up study. PLoS One. 2013;8(10):e78243. https://doi.org/10.1371/journal. pone.0078243.

60. Okoboi S, Ding E, Persuad S, Wangisi J, Birungi J, Shurgold S, et al. Community-based ART distribution system can effectively facilitate long-term program retention and low-rates of death and virologic failure in rural Uganda. AIDS Res Ther. 2015;12:37. https://doi.org/10.1186/s12981-015-0077-4.

61. Wood EM, Zani B, Esterhuizen TM, Young T. Nurse led homebased care for people with HIV/AIDS. BMC Health Serv Res. 2018;18(1):219. https://doi.org/10.1186/s12913-018-3002-4.

62. Tsondai PR, Wilkinson LS, Grimsrud A, Mdlalo PT, Ullauri A, Boulle A. High rates of retention and viral suppression in the scale-up of antiretroviral therapy adherence clubs in Cape Town, South Africa. J Int AIDS Soc. 2017;20(Suppl 4):21649. https://doi. org/10.7448/IAS.20.5.21649.

63. Khabala KB, Edwards JK, Baruani B, Sirengo M, Musembi P, Kosgei RJ, et al. Medication Adherence Clubs: a potential solution to managing large numbers of stable patients with multiple chronic diseases in informal settlements. Tropical Med Int Health. 2015;20(10):1265-70. https://doi.org/10.1111/tmi.12539.

64. Decroo T, Rasschaert F, Telfer B, Remartinez D, Laga M, Ford N. Community-based antiretroviral therapy programs can overcome barriers to retention of patients and decongest health services in sub-Saharan Africa: a systematic review. Int Health. 2013;5(3): 169-79. https://doi.org/10.1093/inthealth/iht016.
65. Boyer S, Protopopescu C, Marcellin F, Carrieri MP, Koulla-Shiro S, Moatti JP, et al. Performance of HIV care decentralization from the patient's perspective: health-related quality of life and perceived quality of services in Cameroon. Health Policy Plan. 2012;27(4): 301-15. https://doi.org/10.1093/heapol/czr039.

66. Mwai GW, Mburu G, Torpey K, Frost P, Ford N, Seeley J. Role and outcomes of community health workers in HIV care in sub-Saharan Africa: a systematic review. J Int AIDS Soc. 2013;16:18586. https:// doi.org/10.7448/IAS.16.1.18586.

67. Grimsrud A, Lesosky M, Kalombo C, Bekker LG, Myer L. Implementation and Operational Research: Community-Based Adherence Clubs for the Management of Stable Antiretroviral Therapy Patients in Cape Town, South Africa: A Cohort Study. J Acquir Immune Defic Syndr. 2016;71(1):e16-23. https://doi.org/ 10.1097/QAI.0000000000000863.

68. Nachega JB, Adetokunboh O, Uthman OA, Knowlton AW, Altice FL, Schechter M, et al. Community-Based Interventions to Improve and Sustain Antiretroviral Therapy Adherence, Retention in HIV Care and Clinical Outcomes in Low- and Middle-Income Countries for Achieving the UNAIDS 90-90-90 Targets. Current HIV/AIDS reports. 2016;13(5):241-55. https://doi.org/10.1007/s11904-016$0325-9$.

69. Tung EL, Thomas A, Eichner A, Shalit P. Implementation of a community pharmacy-based pre-exposure prophylaxis service: a novel model for pre-exposure prophylaxis care. Sex Health. 2018;15(6):556-61. https://doi.org/10.1071/sh18084.

70. Stekler JD, McMahan V, Ballinger L, Viquez L, Swanson F, Stockton J, et al. HIV Pre-exposure Prophylaxis Prescribing Through Telehealth. J Acquir Immune Defic Syndr. 2018;77(5): e40-e2. https://doi.org/10.1097/qai.0000000000001621.

71. Guanira JV, Leigler T, Kallas E, Schechter M, Sharma U, Glidden D, et al. Streamlining HIV Testing for HIV Preexposure Prophylaxis. J Clin Microbiol. 2015;53(1):179-83. https://doi.org/ 10.1128/JCM.01540-14.

72. Estem KS, Catania J, Klausner JD. HIV Self-Testing: a Review of Current Implementation and Fidelity. Current HIV/AIDS reports. 2016;13(2):107-15. https://doi.org/10.1007/s11904-016-0307-y.

73. De Luca A, Zazzi M. Interplay Between Transmitted and Acquired HIV Type 1 Drug Resistance: Reasons for a Disconnect. J Infect Dis. 2015;212(1):5-7. https://doi.org/10.1093/infdis/jiv008.

74. Horizons Population Council ICfRHaCPGH. Adherence to Antiretroviral Therapy Iin Adults: A Guide for Trainers. Mobassa, Kenya. 2004. https://www.popcouncil.org/uploads/pdfs/ horizons/arvadhrnctrngguide.pdf. Accessed 25 May 2018.

75. The United Republic of Tanzania Ministry of Health and Social Welfare National AIDS Control Programme. National Standard Operating Procedures for HIV Care and Treatment. 2013. http:// ihi.eprints.org/1238/1/Adherence_Counselling_for_HIV_Care and Treatment Module 5 march 2013.pdf. Accessed 15 May 2018.

76. Rosen S, Fox MP. Retention in HIV Care between Testing and Treatment in Sub-Saharan Africa: A Systematic Review. PLoS Med. 2011;8(7):e1001056. https://doi.org/10.1371/journal.pmed. 1001056.

77. Haberer JE, Sabin L, Amico KR, Orrell C, Galarraga O, Tsai AC, et al. Improving antiretroviral therapy adherence in resource-limited settings at scale: a discussion of interventions and recommendations. J Int AIDS Soc. 2017;20(1):21371. https://doi.org/10.7448/ ias.20.1.21371.

78. Liegler T, Abdel-Mohsen M, Bentley LG, Atchison R, Schmidt T, Javier J, et al. HIV-1 drug resistance in the iPrEx preexposure prophylaxis trial. J Infect Dis. 2014;210(8):1217-27. https://doi.org/ 10.1093/infdis/jiu233.

79. Lehman DA, Baeten JM, McCoy CO, Weis JF, Peterson D, Mbara $\mathrm{G}$, et al. Risk of drug resistance among persons acquiring HIV within a randomized clinical trial of single- or dual-agent 
preexposure prophylaxis. J Infect Dis. 2015;211(8):1211-8. https:// doi.org/10.1093/infdis/jiu677.

80. Weis JF, Baeten JM, McCoy CO, Warth C, Donnell D, Thomas KK, et al. Preexposure prophylaxis-selected drug resistance decays rapidly after drug cessation. Aids. 2016;30(1):31-5. https://doi.org/10. 1097/qad.0000000000000915.

81. Grant RM, Liegler T, Defechereux P, Kashuba AD, Taylor D, Abdel-Mohsen M, et al. Drug resistance and plasma viral RNA level after ineffective use of oral pre-exposure prophylaxis in women. Aids. 2015;29(3):331-7. https://doi.org/10.1097/qad. 0000000000000556.

82. Haberer JE, Bangsberg DR, Baeten JM, Curran K, Koechlin F, Amico KR, et al. Defining success with HIV pre-exposure prophylaxis: a prevention-effective adherence paradigm. Aids. 2015;29(11):1277-85. https://doi.org/10.1097/qad. 0000000000000647.

83. Delany-Moretlwe S, Cowan FM, Busza J, Bolton-Moore C, Kelley K, Fairlie L. Providing comprehensive health services for young key populations: needs, barriers and gaps. J Int AIDS Soc. 2015;18(2 Suppl 1):19833. https://doi.org/10.7448/IAS.18.2. 19833.

84. Eba PM, Lim H. Reviewing independent access to HIV testing, counselling and treatment for adolescents in HIV-specific laws in sub-Saharan Africa: implications for the HIV response. J Int AIDS Soc. 2017;20(1):21456. https://doi.org/10.7448/IAS.20.1.21456.

85. HIV and adolescents: guidance for HIV testing and counselling and care for adolescents living with HIV: recommendations for a public health approach and considerations for policy-makers and managers. Geneva: World Health Organization. 2013.

86. Muller A, Rohrs S, Hoffman-Wanderer Y, Moult K. "You have to make a judgment call".-Morals, judgments and the provision of quality sexual and reproductive health services for adolescents in South Africa. Soc Sci Med 2016:148:71-8. https://doi.org/10.1016/ j.socscimed.2015.11.048.

87. Fox K, Ferguson J, Ajose W, Singh J, Marum E, Baggaley R. Adolescent consent to testing: a review of current policies and issues in sub-Saharan Africa. HIV and Adolescents: Guidance for HIV Testing and Counselling and Care for Adolescents Living with HIV: Recommendations for a Public Health Approach and Considerations for Policy-Makers and Managers. . Geneva: World Health Organization; 2013.

88. Strode A, Essack Z. Facilitating access to adolescent sexual and reproductive health services through legislative reform: Lessons from the South African experience. S Afr Med J. 2017;107(9): 741-4. https://doi.org/10.7196/SAMJ.2017.v107i9.12525.

89. Tumlinson K, Okigbo CC, Speizer IS. Provider barriers to family planning access in urban Kenya. Contraception. 2015;92(2):14351. https://doi.org/10.1016/j.contraception.2015.04.002.
90. Mahajan AP, Sayles JN, Patel VA, Remien RH, Ortiz D, Szekeres $\mathrm{G}$, et al. Stigma in the HIV/AIDS epidemic: A review of the literature and recommendations for the way forward. AIDS. 2008;22(Suppl 2):S67-79. https://doi.org/10.1097/01.aids. 0000327438.13291 .62 .

91. Famoroti TO, Fernandes L, Chima SC. Stigmatization of people living with HIV/AIDS by healthcare workers at a tertiary hospital in KwaZulu-Natal, South Africa: a cross-sectional descriptive study. BMC Med Ethics. 2013;14(1):S6. https://doi.org/10.1186/ 1472-6939-14-s1-s6.

92. wrong. From caution to urgency: the evolution of HIV testing and counselling in Africa. Bull World Health Organ 2012:90(9):652-8b. https://doi.org/10.2471/blt.11.100818.

93. Chan BT, Tsai AC, Siedner MJ. HIV Treatment Scale-Up and HIVRelated Stigma in Sub-Saharan Africa: A Longitudinal CrossCountry Analysis. Am J Public Health. 2015;105(8):1581-7. https://doi.org/10.2105/AJPH.2015.302716.

94. Chan BT, Tsai AC. HIV stigma trends in the general population during antiretroviral treatment expansion: analysis of 31 countries in sub-Saharan Africa, 2003-2013. J Acquir Immune Defic Syndr. 2016;72(5):558-64. https://doi.org/10.1097/qai. 0000000000001011 .

95. Mack N, Odhiambo J, Wong CM, Agot K. Barriers and facilitators to pre-exposure prophylaxis (PrEP) eligibility screening and ongoing HIV testing among target populations in Bondo and Rarieda, Kenya: Results of a consultation with community stakeholders. BMC Health Serv Res 2014:14:231-. Doi: https://doi.org/10.1186/ 1472-6963-14-231.

96. Peng P, Su S, Fairley CK, Chu M, Jiang S, Zhuang X, et al. A Global Estimate of the Acceptability of Pre-exposure Prophylaxis for HIV Among Men Who have Sex with Men: A Systematic Review and Meta-analysis. AIDS Behav. 2018;22(4):1063-74. https://doi.org/10.1007/s10461-017-1675-z.

97. Blake Helms C, Turan JM, Atkins G, Kempf MC, Clay OJ, Raper JL, et al. Interpersonal Mechanisms Contributing to the Association Between HIV-Related Internalized Stigma and Medication Adherence. AIDS Behav. 2017;21(1):238-47. https://doi.org/10. 1007/s10461-016-1320-2.

98. Golub SA. PrEP Stigma: Implicit and Explicit Drivers of Disparity. Current HIV/AIDS reports. 2018;15(2):190-7. https://doi.org/10. 1007/s11904-018-0385-0 This review article describes how PrEP stigma directly impacts its scalability as a prevention strategy and provides approaches to mitigate stigma associated with PrEP.

99. Calabrese SK, Underhill K. How Stigma Surrounding the Use of HIV Preexposure Prophylaxis Undermines Prevention and Pleasure: A Call to Destigmatize "Truvada Whores". Am J Public Health. 2015;105(10):1960-4. https://doi.org/10.2105/ajph.2015. 302816 . 